\title{
Prazosin for PTSD: Sorting out the evidence
}

Jenna Kendrick, PharmD, Raechel Adamczyk, PharmD, and Christopher Thomas, PharmD, BCPS, BCPP

$\mathrm{M}$ r. $\mathrm{H}$, age 43 , presents to your clinic for management of posttraumatic stress disorder (PTSD). At his last appointment 8 weeks ago, he was continued on fluoxetine, $60 \mathrm{mg} / \mathrm{d}$; he had been stable on this medication for 6 months. Today, $\mathrm{Mr}$. $\mathrm{H}$ reports an increase in the frequency and severity of nightmares. He states that he wakes at least 3 times every week with "disturbing dreams" about his time in the military and does not feel rested even when he sleeps through the night. His ClinicianAdministered PTSD Scale (CAPS) score is 95 on this visit, suggesting extreme PTSD symptomatology. Mr. $\mathrm{H}$ asks if anything can be done to reduce the frequency and intensity of his nightmares.

PTSD is the development of characteristic symptoms following exposure to $\geq 1$ traumatic events. According to DSM-5, PTSD symptoms include the presence of $\geq 1$ intrusion symptoms (recurrent, intrusive memories of the traumatic event; recurrent distressing dreams; dissociative

Dr. Kendrick is a PGY-2 Psychiatric Pharmacy Resident, Chillicothe VA Medical Center, Chillicothe, Ohio. Dr. Adamczyk is a PGY-2 Psychiatric Pharmacy Resident, Chillicothe VA Medical Center, Chillicothe, Ohio. Dr. Thomas is the PGY-1 and PGY-2 Residency Program Director, Chillicothe VA Medical Center, Chillicothe, Ohio, and Clinical Associate Professor of Pharmacology, Ohio University of Osteopathic Medicine, Athens, Ohio.

Disclosures

The authors report no financial relationships with any companies whose products are mentioned in this article, or with manufacturers of competing products. The contents of this article do not represent the views of the US Department of Veterans Affairs or the United States Government. This material is the result of work supported with resources and the use of facilities at the Chillicothe Veterans Affairs Medical Center in Chillicothe, Ohio. The case presented is a fictional case and does not represent a specific case or person(s).

doi: 10.12788/cp.0117 reactions), persistent avoidance of stimuli, negative alterations in cognition and mood, and marked alterations in arousal and reactivity associated with the traumatic event(s). ${ }^{1}$ The symptoms must be present for $>1$ month, cause clinically significant distress or impairment in functioning, and not be attributable to the psychologic effects of a substance or medical conditions. ${ }^{1}$ This article focuses specifically on the hyperarousal symptoms, and the clinical controversies surrounding the use of prazosin for PTSD.

\section{Prazosin for PTSD treatment}

Sleep disorders are extremely common in patients with PTSD. Up to $90 \%$ of patients report sleep disturbances, and up to $70 \%$ report nightmares. ${ }^{2}$ Prazosin has been widely used in the treatment of PTSD-related sleep disorders and nightmares. The American Psychiatric Association $^{3}$ and the British Association

\section{Practice Points}

- The PACT trial suggests prazosin does not improve PTSD symptoms, but these results should be interpreted with caution.

\section{- Before prescribing prazosin for} patients with PTSD who experience sleep disturbances, discuss the risks and benefits.

\section{- Initiate prazosin at a low dose} (1 $\mathbf{~ m g} / \mathbf{d}$ ) and titrate to clinical effect.

- Refer patients with PTSD to evidencebased psychotherapy.

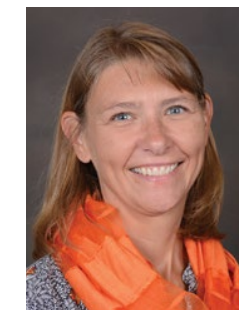

Vicki L. Ellingrod, PharmD, FCCP Department Editor
Savvy Psychopharmacology is produced in partnership with the College of Psychiatric and Neurologic Pharmacists cpnp.org mhc.cpnp.org (journal) 


\section{Clinical Point}

\section{Before prescribing prazosin for patients with PTSD who have sleep disturbances, discuss the risks and benefits}

Discuss this article at www.facebook.com/ MDedgePsychiatry of Psychopharmacology $y^{4}$ guidelines include prazosin as a first-line recommendation for treatment of PTSD. However, updated 2017 guidelines from the Veterans Affairs/Department of Defense (VA/ DoD) ${ }^{5}$ and data from the 2018 Prazosin and Combat Trauma PTSD (PACT) trial ${ }^{6}$ contradict these original recommendations. Previously, the 2010 VA/DoD guideline said prazosin had insufficient evidence for monotherapy, but recommended it as adjunctive treatment for sleep and nightmares. ${ }^{7}$ The updated 2017 VA/DoD guideline recommends "weak against" prazosin use for global symptoms of PTSD, and says there is insufficient evidence for its use in nightmares. ${ }^{5}$ Below we summarize the findings of studies that contributed to those original recommendations, along with results of the PACT trial.

Raskind et al ${ }^{8,9}$ conducted 2 studies of prazosin use in combat veterans with PTSD. In both studies, prazosin had significant positive effects on the ClinicianAdministered PTSD Scale (CAPS) and Clinical Global Impression of Change (CGIC) scores. ${ }^{8,9}$ The 2007 study also found significant effects of prazosin on Pittsburgh Sleep Quality Index (PSQI) scores. ${ }^{9}$

Raskind et al ${ }^{10}$ conducted another study in 2013 of prazosin use for active-duty soldiers who had combat trauma PTSD with nightmares. Prazosin had positive effects for nightmares, sleep quality, and CAPS scores. ${ }^{10}$

Germain et $a l^{11}$ reviewed prazosin for treating sleep disturbances in US military veterans. Prazosin was associated with significant improvements in insomnia and daytime PTSD symptom severity as demonstrated by changes in PSQI and CAPS scores. ${ }^{11}$

Taylor et $a l^{12}$ examined the effects of prazosin on sleep measures and clinical symptoms in civilians with PTSD. Prazosin significantly increased total sleep time, rapid eye movement sleep time, and CGIC scores while significantly decreasing trauma-related nightmares. ${ }^{12}$
Overall, these trials found efficacy for the use of prazosin for patients diagnosed with PTSD; however, the population size in each of these studies was small.

\section{Results of the PACT trial}

The PACT trial was a 26-week, multicenter, double-blind, randomized, placebo-controlled trial conducted across 12 VA medical centers. ${ }^{6}$ During the first 5 weeks, participants were randomized to receive placebo or prazosin, which could be titrated up to $20 \mathrm{mg} / \mathrm{d}$ in men and 12 $\mathrm{mg} / \mathrm{d}$ in women. Participants remained on that dose from the end of Week 5 through Week 10. At that time, other pharmacologic therapies and psychotherapy could be added, discontinued, or adjusted. The mean maintenance total daily dose of prazosin was $14.8 \mathrm{mg}$.

A total of 413 patients were screened, 304 were randomized (152 per group), and 271 completed the 10-week primary outcome assessment. The population was almost entirely male (96.1\% in the prazosin group and $99.3 \%$ in the placebo group), and most participants were White $(64.5 \%$ in the prazosin group and $69.1 \%$ in the placebo group), with an average age of approximately 50 years. Primary outcomes included change from baseline to Week 10 in both CAPS item B2 ("recurrent distressing dreams") and PSQI scores. CGIC score was evaluated at Week 10.

At Week 10, none of the primary outcomes were found to be statistically significant. The mean difference in change from baseline to Week 10 in CAPS item B2 score and PSQI score were $0.2(P=.38)$ and 0.1 $(P=.80)$, respectively. There was no significant difference in mean CGIC scores $(P=.96)$. Repeated measures of CAPS item B2, PSQI, and CGIC scores were conducted through Week 26 as secondary outcomes. No significant differences were found. This study concluded that prazosin did not alleviate distressing dreams, improve sleep quality, or improve overall clinical symptoms. ${ }^{6}$ 


\section{The PACT trial: Strengths and weaknesses}

The PACT trial is the largest placebo-controlled trial for prazosin use in PTSD to date. It failed to show efficacy of prazosin for PTSD-associated nightmares, which contradicts previous studies. Although the mean total daily dose of prazosin was adequate and primary outcomes were measured with appropriate scales, the study failed to enroll the desired number of patients, which increased the possibility of false-negative results. Furthermore, participant recruitment may have led to selection bias because all participants were clinically stable, which could explain the lack of efficacy. However, the average CAPS scores were 80.7 in the prazosin group and 81.9 in the placebo group, which indicates that these patients had significant symptomatology at baseline and before entering the study.

A major theme of studies evaluating prazosin treatment for PTSD is a focus on a military population and military-related trauma. Other than Taylor et $\mathrm{al}^{12}(\mathrm{~N}=13)$, none of these trials included patients who were diagnosed with PTSD due to other traumas, such as sexual trauma, which limits the generalizability of the results. Furthermore, apart from the PACT trial, none of these studies had $>100$ participants, which further reduces external validity. Current guidelines have not been updated to include the results of the PACT trial, and it is unclear if the results of this trial are strong enough to change clinical practice.

\section{CASE CONTINUED}

To ensure patient-centered care, the treating clinicians conduct a risk/benefit discussion with the patient regarding starting prazosin. Mr. H opts to try prazosin, so the clinicians initiate a low dose $(1 \mathrm{mg} / \mathrm{d})$ to mitigate adverse effects, and plan to titrate to clinical effect or intolerability. Per evidence from the trials discussed, it is likely Mr. $\mathrm{H}$ will need to

\section{Related Resource}

- North CS, Hong BA, Downs DL. PTSD: A systematic approach to diagnosis and treatment. Current Psychiatry 2018;17(4):35-43

Drug Brand Names

Fluoxetine - Prozac

Prazosin - Minipress

be titrated to at least 5 to $6 \mathrm{mg} / \mathrm{d}$ to see a clinical effect.

\section{References}

1. Diagnostic and statistical manual of mental disorders, 5 th ed. American Psychiatric Association; 2013.

2. Maher MJ, Rego SA, Asnis, GM. Sleep disturbances in patients with post-traumatic stress disorder: epidemiology, impact and approaches to management. CNS Drugs. 2006;20(7):567-590.

3. Benedek DM, Friedman MJ, Zatzick D, et al. Guideline watch (March 2009): Practice guideline for the treatment of patients with acute stress disorder and posttraumatic stress disorder. APA Practice Guidelines. Published 2010. Accessed March 14 2021. https://psychiatryonline.org/pb/assets/raw/sitewide/ practice_guidelines/guidelines/acutestressdisorderptsdwatch.pdf

4. Baldwin DS, Anderson IM, Nutt DJ, et al. Evidence-based pharmacological treatment of anxiety disorders, post-traumatic stress disorder and obsessive-compulsive disorder: a revision of the 2005 guidelines from the British Association for Psychopharmacology. J Psychopharmacol. 2014;28(5):403-439. doi: $10.1177 / 0269881114525674$

5. Department of Veterans Affairs, Department of Defense. $\mathrm{VA} / \mathrm{DoD}$ clinical practice guideline for the management of posttraumatic stress disorder and acute stress disorder. Version 3.0. Published 2017. Accessed February 5, 2021. https://www.healthquality.va.gov/guidelines/MH/ptsd/ VADoDPTSDCPGFinal012418.pdf

6. Raskind MA, Peskind ER, Chow B, et al. Trial of prazosin for post-traumatic stress disorder in military veterans. $\mathrm{N}$ Engl J Med. 2018;378(6):507-517.

7. Department of Veterans Affairs, Department of Defense. VA/ DoD clinical practice guideline: management of post-traumatic stress. Version 2.0. Published 2010. Accessed February 5, 2021. https://www.healthquality.va.gov/guidelines/MH/ptsd/ cpg_PTSD-full-201011612.PDF

8. Raskind MA, Peskind ER, Katner ED, et al. Reduction of nightmares and other PTSD symptoms in combat veterans by prazosin: a placebo-controlled study. Am J Psychiatry. 2003;160(2):371-373.

9. Raskind MA, Peskind ER, Hoff DJ, et al. A parallel group placebo-controlled study of prazosin for trauma nightmares and sleep disturbance in combat veterans with post-traumatic stress disorder. Biol Psychiatry. 2007;61(8):928-934.

10. Raskind MA, Peterson K, Williams T, et al. A trial of prazosin for combat trauma PTSD with nightmares in active-duty soldiers returned from Iraq and Afghanistan. Am J Psychiatry. 2013;170(9):1003-1010.

11. Germain A, Richardson R, Moul DE, et al. Placebo-controlled comparison of prazosin and cognitive-behavioral treatments for sleep disturbances in US military veterans. J Psychosom Res. 2012;72(2):89-96.

12. Taylor FB, Martin P, Thompson C, et al. Prazosin effects on objective sleep measures and clinical symptoms in civilian trauma posttraumatic stress disorder: a placebo-controlled study. Biol Psychiatry. 2008;63(6):629-632.

\section{Clinical Point}

Although the PACT trial found prazosin does not improve PTSD symptoms, these results should be interpreted with caution 